\title{
Mortality and Morbidity after Cytoreductive Surgery and Hyperthermic Intraperitoneal Chemotherapy for Peritoneal Carcinomatosis
}

\author{
Akshat Saxena David L. Morris \\ UNSW Department of Surgery, St George Hospital, Kogarah, New South Wales, Australia
}

\section{Keywords}

Morbidity · Mortality · Cytoreductive surgery ·

Hyperthermic intraperitoneal chemotherapy

\section{Summary}

Background: Cytoreductive surgery (CRS) combined with hyperthermic intraperitoneal chemotherapy (HIPEC) is associated with improved survival in selected patients with peritoneal carcinomatosis. This treatment, however, has been associated with a relatively high rate of perioperative mortality and morbidity. Method: A review of clinical studies before March 2013 was performed to examine the impact of CRS-HIPEC on early mortality and morbidity. Factors associated with a poor perioperative outcome were identified. The importance of the learning curve was examined. Clinical outcomes were synthesized through a narrative review. Results: In-hospital mortality in high-level centres (>100 patients) ranged from 0.9 to $5.8 \%$. The morbidity rate ranged from 36 to $84 \%$; the overall rate of major or grade III/IV morbidity ranged from 0 to $52 \%$. Factors that were consistently associated with a poor perioperative outcome included extensive peritoneal disease and markers of increased operative effort such as operation length, blood loss, and number of peritonectomy procedures performed. Several studies showed that morbidity decreases as operating volume increases. Moving forward, there is a need to evaluate strategies to reduce perioperative mortality whilst not compromising oncological outcomes. Conclusion: CRS-HIPEC is associated with an acceptable rate of perioperative mortality and morbidity. Morbidity decreases with increased experience and is strongly associated with the extent of disease.

\author{
Schlüsselwörter \\ Morbidität · Mortalität · Zytoreduktive Chirurgie · \\ Hypertherme intraperitoneale Chemotherapie
}

\section{Zusammenfassung}

Hintergrund: Die zytoreduktive Chirurgie (CRS) in Kombination mit hyperthermer intraperitonealer Chemotherapie (HIPEC) ist mit verbessertem Überleben bei selektionierten Patienten mit Peritonealkarzinose assoziiert. Gleichzeitig wird diese Behandlungsmethode jedoch mit relativ hoher perioperativer Mortalität und Morbidität in Verbindung gebracht. Methode: Es wurde eine Übersicht klinischer Studien bis März 2013 durchgeführt, um die Auswirkung der CRS-HIPEC auf die frühe Mortalität und Morbidität zu untersuchen. Mit schlechterem perioperativen Outcome assoziierte Faktoren wurden identifiziert. Die Bedeutung der Lernkurve wurde untersucht. Die klinischen Verläufe wurden mittels eines narrativen Reviews erstellt. Ergebnisse: Die krankenhausinterne Mortalität in Zentren mit >100 Patienten (high level) war 0,95,8\%. Die Morbiditätsrate war 36-84\%; die Gesamtrate der hochgradigen Morbidität bzw. Morbidität vom Grad III/IV war 0-52\%. Beständig mit schlechterem perioperativen Outcome assoziierte Faktoren waren ein extensiver Befall des Peritoneums sowie Marker erhöhten chirurgischen Aufwands wie Dauer der Operation, Blutverlust und Zahl der durchgeführten Peritonektomien. Mehrere Studien haben gezeigt, dass die Morbidität abnimmt, wenn das Operationsvolumen zunimmt. Im weiteren Verlauf sollten Strategien zur Verminderung der perioperativen Mortalität ohne ein gleichzeitiges Kompromittieren des onkologischen Outcomes untersucht werden. Schlussfolgerung: CRS-HIPEC ist mit akzeptabler perioperativer Mortalität und Morbidität verbunden. Die Morbidität nimmt mit steigender Erfahrung ab und ist stark mit dem Erkrankungsausmaß assoziiert.

\section{KARGER \\ Fax +497614520714 \\ Information@Karger.com}

www.karger.com (c) 2013 S. Karger GmbH, Freiburg

$1662-6664 / 13 / 0294-0231 \$ 38.00 / 0$

Accessible online at:

www.karger.com/vim
Dr. David Lawson Morris, MD, PhD

UNSW Department of Surgery

St George Hospital

Kogarah, 2217, NSW, New South Wales, Australia

david.morris@unsw.edu.au 


\section{Introduction}

Cytoreductive surgery (CRS) combined with hyperthermic intraperitoneal chemotherapy (HIPEC) is a potentially curative treatment for peritoneal carcinomatosis. Across a variety of disease types, including colorectal cancer, peritoneal mesothelioma, and appendiceal neoplasms, the combination of CRS-HIPEC has consistently demonstrated improved survival outcomes [1-3]. There is randomized evidence demonstrating the superiority of CRS-HIPEC for colorectal cancer peritoneal carcinomatosis [3]. Verwaal et al. [3] showed a median survival of 22 months in patients treated with CRSHIPEC compared to 12 months in patients treated conservatively. Elias et al. [4] achieved a 5-year survival of $65 \%$ in patients with CRC, who had a complete cytoreduction. Recent prospective and observation series have also reported promising outcomes with a 5-year survival ranging from 25 to $40 \%$ in patients who have had a complete cytoreduction [5-7]. For peritoneal mesothelioma, a multi-institutional study of 405 patients demonstrated a median survival of 53 months with a 5 -year survival of $47 \%$ [2]. More recently, a collective analysis of the outcomes of 2,298 patients with pseudomyxoma peritonei showed a median survival of 196 months with a 10-year survival of $63 \%$ [1]. For peritoneal carcinomatosis secondary to other disease entities such as ovarian cancer and gastric cancer, there is less quality evidence on the efficacy of CRSHIPEC although studies have also been very promising $[8,9]$. CRS-HIPEC has also been shown to be cost-effective [10]. Despite encouraging survival outcomes, CRS-HIPEC as a combined modality has been criticised for being a morbid procedure. The aim of this review is to evaluate the perioperative outcomes following CRS-HIPEC for peritoneal malignancies.

\section{A Summary of Mortality and Morbidity}

Studies have consistently demonstrated high rates of perioperative morbidity after CRS-HIPEC. A critical appraisal of the literature published in 2010 showed that mortality ranged between $0-17 \%$ [11]. A closer analysis of that review showed interesting results. Variability in rates of reported mortality was significantly less when only studies with $>100$ patients were included $(0.9-5.8 \%)$. The most common causes of perioperative mortality were sepsis and multi-organ failure as a result of surgical complications. The overall morbidity rate ranged from 36 to $84 \%$; the rate of major or grade III/IV morbidity ranged from 0 to $52 \%$. In institutions which were regarded as tertiary high-volume centres, the rate of major or grade III/IV morbidity ranged from 12 to $52 \%$. The reoperation rates following treatment that occurred during the perioperative period ranged from 0 to $23 \%$. The mean length of intensive care unit stay ranged from 1 to 5 days. The mean length of stay in hospital ranged from 7 to 48 days. The review evaluated specific complications. The most common postoperative complications were sepsis ranging from 0 to $14 \%$, fistula 0 to $23 \%$, abscess 0 to $37 \%$, ileus 0 to $86 \%$, perforation 0 to $10 \%$, anastomotic leak 0 to $9 \%$, deep venous thrombosis/ pulmonary embolus 0 to $9 \%$, haematological toxicity 0 to $28 \%$, and renal insufficiency 0 to $7 \%$. A comprehensive knowledge and appreciation of the management of these complications is required in any centre specialising in the management of peritoneal carcinomatosis using CRS-HIPEC. Less common complications include respiratory events $(0$ $11 \%)$, pancreatic fistula (0-6.3\%), and cardiac complications (0-3\%).

When referring to single studies, there is a need to refer to publications from high-volume institutions or those reflecting a multi-institutional experience. The recent review of 2,298 patients with pseudomyxoma peritonei treated with CRSHIPEC demonstrated an overall mortality of only $2 \%$ and major (grade III/IV/V) morbidity of $24 \%$ [1]. A French multiinstitutional study of 1,290 patients demonstrated an overall mortality of $4 \%$ and major morbidity (grade III/IV) of $33.6 \%$ [12]. Reoperation was necessary in $14 \%$ of patients. Neutropenia was the principal complication $(13 \%)$, and digestive fistula occurred in $10 \%$ of patients. The average length of hospitalisation was 24 days. In our analysis of 243 patients across all disease types, overall mortality was $3 \%$ with a grade III/IV morbidity of $43 \%$ [13]. The impact of iterative CRS on perioperative mortality and morbidity is a topic of clinical significance. Fortunately, most published studies have shown that iterative CRS is both safe and efficacious in selected patients with peritoneal carcinomatosis $[14,15]$.

The analysis of individual studies demonstrates the lack of standardization in the reporting of adverse events between studies. Although the NCI Common Toxicity Criteria are used by most institutions, the classification of morbidities has not been consistent across all studies. Moreover, variation in surgical practice between institutions, for example, whether to drain collections or manage them conservatively, affects the reporting of morbidity outcomes. What is clear in most large studies is that whilst morbidity is high after CRS-HIPEC, overall mortality remains low, especially in high-volume centres.

\section{Factors Associated with Mortality and Morbidity}

Identifying factors associated with a poorer perioperative outcome is important. Several studies have specifically evaluated the risk factors for perioperative complications across a variety of disease subtypes. Evidence regarding the impact of advanced age or early postoperative intraperitoneal chemotherapy (EPIC) on postoperative outcomes is equivocal [12, 13]. What has been consistently reported, however, is that the extent of peritoneal disease, and markers of increased operative efforts such as operation length, blood loss and number of 
peritonectomy procedures performed, have been consistently associated with a poorer perioperative outcome [12, 16-20]. There is also data suggesting that cytoreduction in certain anatomical regions, in particular, the left upper quadrant, is associated with increased morbidity $[14,16]$. Routinely collected preoperative variables may also help identify those patients at an increased risk of perioperative morbidity. The American Society of Anesthesiologists (ASA) score is a simple calculation of a patient's fitness for surgery. In our earlier analysis of 145 patients with pseudomyxoma peritonei, eight factors were associated with grade IV/V morbidity on univariate analysis: peritoneal cancer index $\geq 21(\mathrm{p}=0.034)$, ASA score $\geq 3$ $(\mathrm{p}=0.003)$, operation duration $\geq 10 \mathrm{~h}(\mathrm{p}<0.001)$, left upper quadrant peritonectomy procedure $(\mathrm{p}=0.037)$, colonic resection $(p=0.012)$, ostomy $(p=0.005)$, ileostomy $(p=0.012)$, and transfusion $\geq 6$ units $(\mathrm{p}=0.011)$ [16]. Multivariate analysis showed only two significant risk factors for grade IV/V morbidity: $\mathrm{ASA} \geq 3(\mathrm{p}=0.006)$ and an operation length $\geq 10 \mathrm{~h}$ $(p<0.001)$. The fact that a simple score such as the ASA may accurately predict patient outcomes suggests the utility of simple scoring systems for the preoperative assessment of risk. This requires further study. The impact of other factors, such as type of intraperitoneal chemotherapy, nutritional status, preoperative chemotherapy and intraoperative red blood cell transfusion, requires further investigation. It must be noted that many factors associated with a poorer perioperative outcome, in particular high-volume peritoneal disease and extensive cytoreduction, also portend a poorer survival. In light of this, and given the importance of patient selection, a careful approach should be adopted by clinicians in selecting patients with high-volume disease for surgery.

\section{Importance of Learning Curve}

Although studies have demonstrated that CRS-HIPEC remains a morbid procedure, it is also clear that a 'learning curve' exists. That is, morbidity decreases as operating volume increases. Several explanations have been proposed including, but not limited to, improved surgical technique, preoperative management, and more stringent patient selection. A leading Dutch group demonstrated that over a period of 10 years, where 323 procedures were performed, improvements in the patient selection process resulted in decreased postoperative morbidity rates and median duration of hospital stay [21]. Moran et al. [22] reported a decrease in perioperative mortality from 18 to $3 \%$. We previously reported similar findings. In our initial experience of 140 patients, there was a reduced rate of perioperative mortality, severe morbidity, delayed morbidity, intensive care unit stay, and transfusion requirement, over time. The recent systematic review on the treatment of pseudomyxoma peritonei using CRS-HIPEC demonstrated the importance of the learning curve in that the morbidity outcomes were significantly lower in established centres compared to emerging units (35 vs. $23 \%$; p < 0.001 ). The situation regarding CRS-HIPEC then is not to dissimilar to that faced by surgeons performing pancreaticoduodenectomy for pancreatic malignancies. Initial reports showed a very high rate of perioperative mortality after pancreaticoduodenectomy of up to $30 \%$ [23]. In the years since, with continuous advancements in surgical technique and optimization of patient selection, this procedure has evolved into a relatively safe one with perioperative mortality of $1-5 \%$ [23]. It is likely, therefore, that in time CRS-HIPEC will be associated with significantly better perioperative outcomes than now. Further outcome-based research from the various institutions using CRS-HIPEC is required to ascertain the true impact of the 'learning curve' on perioperative outcomes.

\section{Gastrointestinal and Haematological Toxicities}

Several studies have sought to investigate the impact of CRS-HIPEC on specific toxicities. Haematological toxicity has been well investigated in the literature. Despite the use of intraperitoneal chemotherapy, which theoretically should minimise systemic chemotoxicity, CRS-HIPEC can result in myelosuppression. The incidence of haematological toxicity varies widely between $0-28 \%$ but is nevertheless an important complication after CRS-HIPEC [1]. Severe myelosuppression in the acute postoperative phase puts the patient at risk for life-threatening sepsis, poor wound healing, and other significant complications. A $66 \%$ mortality rate was reported for HIPEC-induced neutropenia in a small group of patients treated with HIPEC [24]. Recent studies have suggested that splenectomy may ameliorate haematological toxicity secondary CRS-HIPEC although this procedure in itself is associated with morbidities including atelectasis, pleural effusion, pancreatic injury, subphrenic abscess, and pancreatic pseudocyst formation [25]

Gastrointestinal (GIT) complications expectedly account for much of the morbidity after CRS-HIPEC. Casado-Adam et al. [26] specifically evaluated GIT complications after CRSHIPEC. The overall incidence of GIT complications was $17 \%$; the incidence of grade III/IV complications was $8 \%$. The most common GIT complications were anastomotic failures and digestive fistula. On multivariate analysis, the extent of peritoneal disease was the only independent risk factor for GIT complications. In other studies, the incidence of grade III/IV GIT complications has ranged from 4.5 to $19 \%$ [26]. Pancreatic fistula after CRS-HIPEC has been investigated in at least 2 studies $[27,28]$. We showed that up to $6.3 \%$ of patients developed postoperative pancreatic fistulas; the majority of patients improved with conservative therapy [27]. The association of CRS-HIPEC with other morbidities still requires further study. 


\section{Conclusion}

CRS-HIPEC is an efficacious treatment for selected patients with peritoneal carcinomatosis. It is, however, associated with a high rate of perioperative morbidity. Improvements in patient selection, perioperative management, and improved surgical skill as part of the learning curve will in- variably reduce the morbidity associated with this procedure in the future.

\section{Disclosure Statement}

The authors have no disclosures.

\section{References}

1 Chua TC, Moran BJ, Sugarbaker PH, et al.: Earlyand long-term outcome data of patients with pseudomyxoma peritonei from appendiceal origin treated by a strategy of cytoreductive surgery and hyperthermic intraperitoneal chemotherapy. J Clin Oncol 2012;30:2449-2456.

2 Yan TD, Deraco M, Baratti D, et al.: Cytoreductive surgery and hyperthermic intraperitoneal chemotherapy for malignant peritoneal mesothelioma: multi-institutional experience. J Clin Oncol 2009;27:6237-6242.

3 Verwaal VJ, van Ruth S, de Bree E, et al.: Randomized trial of cytoreduction and hyperthermic intraperitoneal chemotherapy versus systemic chemotherapy and palliative surgery in patients with peritoneal carcinomatosis of colorectal cancer. J Clin Oncol 2003;21:3737-3743.

4 Elias D, Lefevre JH, Chevalier J, et al.: Complete cytoreductive surgery plus intraperitoneal chemohyperthermia with oxaliplatin for peritoneal carcinomatosis of colorectal origin. J Clin Oncol 2009; 27:681-685.

5 Yan TD, Morris DL: Cytoreductive surgery and perioperative intraperitoneal chemotherapy for isolated colorectal peritoneal carcinomatosis: experimental therapy or standard of care? Ann Surg 2008;248:829-835.

6 De Cuba EM, Kwakman R, Knol DL, Bonjer HJ, Meijer GA, Te Velde EA: Cytoreductive surgery and HIPEC for peritoneal metastases combined with curative treatment of colorectal liver metastases: systematic review of all literature and metaanalysis of observational studies. Cancer Treat Rev 2013;39:321-327.

7 Newman NA, Votanopoulos KL, Stewart JH, Shen $\mathrm{P}$, Levine EA: Cytoreductive surgery and hyperthermic intraperitoneal chemotherapy for colorectal cancer. Minerva Chir 2012;67:309-318.

8 Glockzin G, Piso P: Current status and future directions in gastric cancer with peritoneal dissemination. Surg Oncol Clin N Am 2012;21:625-33.

$\checkmark$ Helm CW: Current status and future directions of cytoreductive surgery and hyperthermic intraperitoneal chemotherapy in the treatment of ovarian cancer. Surg Oncol Clin N Am 2012;21:645-663.

10 Chua TC, Martin S, Saxena A, et al.: Evaluation of the cost-effectiveness of cytoreductive surgery and hyperthermic intraperitoneal chemotherapy (peritonectomy) at the St George Hospital peritoneal surface malignancy program. Ann Surg 2010;251: 323-329.
Chua TC, Yan TD, Saxena A, Morris DL: Should the treatment of peritoneal carcinomatosis by cytoreductive surgery and hyperthermic intraperitoneal chemotherapy still be regarded as a highly morbid procedure?: a systematic review of morbidity and mortality. Ann Surg 2009;249:900-907.

12 Glehen O, Gilly FN, Boutitie F, et al.: Toward curative treatment of peritoneal carcinomatosis from nonovarian origin by cytoreductive surgery combined with perioperative intraperitoneal chemotherapy: a multi-institutional study of 1,290 patients. Cancer 2010;116:5608-5618.

13 Chua TC, Saxena A, Schellekens JF, et al.: Morbidity and mortality outcomes of cytoreductive surgery and perioperative intraperitoneal chemotherapy at a single tertiary institution: towards a new perspective of this treatment. Ann Surg 2010;251: 101-106.

14 Saxena A, Yan TD, Morris DL: Critical assessment of preoperative and operative risk factors for complications after iterative peritonectomy procedures. Eur J Surg Oncol 2010;36:309-314.

15 Golse N, Bakrin N, Passot G, et al.: Iterative procedures combining cytoreductive surgery with hyperthermic intraperitoneal chemotherapy for peritoneal recurrence: postoperative and long-term results. J Surg Oncol 2012;106:197-203.

16 Saxena A, Yan TD, Chua TC, Morris DL: Critical assessment of risk factors for complications after cytoreductive surgery and perioperative intraperitoneal chemotherapy for pseudomyxoma peritonei. Ann Surg Oncol 2010;17:1291-1301.

17 Mizumoto A, Canbay E, Hirano M, et al.: Morbidity and mortality outcomes of cytoreductive surgery and hyperthermic intraperitoneal chemotherapy at a single institution in Japan. Gastroenterol Res Pract 2012;2012:836425.

-18 Yan TD, Zappa L, Edwards G, Alderman R, Marquardt CE, Sugarbaker PH: Perioperative outcomes of cytoreductive surgery and perioperative intraperitoneal chemotherapy for non-appendiceal peritoneal carcinomatosis from a prospective database. J Surg Oncol 2007;96:102-112.
19 Verwaal VJ, van Tinteren H, Ruth SV, Zoetmulder FA: Toxicity of cytoreductive surgery and hyperthermic intra-peritoneal chemotherapy. J Surg Oncol 2004;85:61-67.

20 Elias D, Goere D, Blot F, et al.: Optimization of hyperthermic intraperitoneal chemotherapy with oxaliplatin plus irinotecan at 43 degrees $\mathrm{C}$ after compete cytoreductive surgery: mortality and morbidity in 106 consecutive patients. Ann Surg Oncol 2007;14:1818-1824.

21 Smeenk RM, Verwaal VJ, Zoetmulder FA: Learning curve of combined modality treatment in peritoneal surface disease. Br J Surg 2007;94:1408-1414.

22 Moran BJ: Decision-making and technical factors account for the learning curve in complex surgery. J Public Health (Oxf) 2006;28:375-378.

23 Winter JM, Cameron JL, Campbell KA, et al. 1,423 pancreaticoduodenectomies for pancreatic cancer: a single-institution experience. J Gastrointest Surg 2006;10:1199-210; discussion 210-211.

24 Schnake KJ, Sugarbaker PH, Yoo D: Neutropenia following perioperative intraperitoneal chemotherapy. Tumori 1999;85:41-46.

25 Becher RD, Shen P, Stewart JH, Russell G, Bradley JF, Levine EA: Splenectomy ameliorates hematologic toxicity of hyperthermic intraperitoneal chemotherapy. J Gastrointest Oncol 2011;2:70-76.

26 Casado-Adam A, Alderman R, Stuart OA, Chang D, Sugarbaker PH: Gastrointestinal complications in 147 consecutive patients with peritoneal surface malignancy treated by cytoreductive surgery and perioperative intraperitoneal chemotherapy. Int J Surg Oncol 2011;2011:468698.

27 Saxena A, Chua TC, Yan TD, Morris DL: Postoperative pancreatic fistula after cytoreductive surgery and perioperative intraperitoneal chemotherapy: incidence, risk factors, management, and clinical sequelae. Ann Surg Oncol 2010;17:1302-1310.

28 Kusamura S, Baratti D, Antonucci A, et al.: Incidence of postoperative pancreatic fistula and hyperamylasemia after cytoreductive surgery and hyperthermic intraperitoneal chemotherapy. Ann Surg Oncol 2007;14:3443-3452. 